\title{
Living with uncertainty: antidepressants and pregnancy
}

Ian Jones and Liz McDonald

\section{Summary}

There have been a large number of studies in recent years reporting on the reproductive safety of antidepressant medication. Some studies, but not all, have reported an association of antidepressant exposure in pregnancy and the subsequent development of autism spectrum disorders. It remains difficult to know whether the modest increase in risk is due to the medication, to the mood disorder itself, or to other confounding factors. For any individual woman the decision to commence or continue antidepressant medication in pregnancy must be made after a full consideration of the potential risks and benefits of all options, including non-pharmacological treatments.
In making these difficult decisions it is important to recognise that episodes of severe psychiatric illness may have very serious negative consequences for the woman, her baby and her family, and these must be weighed against what is known about the risks of taking medication.

\section{Declaration of interest}

I.J. has received honoraria from Lilly, GlaxosmithKline, Lundbeck, Janssen, and AstraZeneca for giving talks on psychoeducation for bipolar disorder and his research on prenatal psychosis

\section{What do we know about antidepressants and pregnancy?}

Before 2005, discussing antidepressant use in pregnancy with women was in many ways easier than it is today. The limited evidence base at that time did not suggest that antidepressants were major teratogens and there was no suggestion of longer-term influences on development for exposed children. The evidence base, however, consisted of small studies and case reports, with power only to detect major effects. By 2007 that had all changed with the publication of two studies finding that a particular medication, paroxetine, when used in pregnancy was associated with an increased risk of cardiac defects. ${ }^{1,2}$ Over the past 7 years a number of further studies have been published on the reproductive safety of antidepressant medication, some including very large numbers, with one reporting on over 30000 antidepressant exposures. ${ }^{3}$ Despite this considerable increase in data, it is still difficult to be sure whether antidepressants are associated with an increased risk of congenital malformations. A recent meta-analysis, although finding no increase in congenital malformations in general, found a statistically significant increase in cardiovascular malformations but concluded that this may be the result of uncontrolled confounders. It also suggested that this small increase in risk, although statistically significant, was not clinically significant. ${ }^{4}$

The potential risks associated with antidepressants taken in pregnancy are not limited to teratogenicity and issues of neonatal withdrawal and of longer-term effects on cognitive development or behaviour must also be considered. In the past couple of years a number of studies, including the paper in this month's Journal, have reported an association between exposure to selective serotonin reuptake inhibitor (SSRI) medication in pregnancy and a higher risk of autism spectrum disorder (ASD) in children. ${ }^{5-7}$ This is certainly a potentially worrying development but the cause of this relationship remains uncertain.

†See pp. 95-102 and 105-106, this issue.

\section{What may account for these findings?}

Association does not prove causality, however. It is possible that the higher risk of autism is due to the SSRIs, but it may also be due to the effects of the mood disorder for which the medication has been prescribed. Given that some family studies show increased rates of mood disorder in the parents of children with autism, it is also possible that an overlap in genetic factors between mood disorders and ASD is also involved. In the study by El Marroun et al, for example, depressive symptoms in pregnancy that were not treated with antidepressants were also associated with a subsequent risk of autism. Although the risk was higher for the group treated with SSRIs, it is possible that this reflects an increased severity of depression in the women taking medication.

Other factors found more commonly in women prescribed SSRI medication (e.g. smoking, alcohol use, obesity, poor diet) may also account for the increased risk. A recently published study of 666468 children born in Denmark provides some reassurance that the association may not be due to the medication itself. It found that after controlling for confounding factors there was no significant association between prenatal exposure to SSRI medication and ASD. ${ }^{8}$ A subsequent study employing the same Danish registry data also found no significant association when attempts were made to control for confounding by indication. ${ }^{9}$

\section{How should we respond?}

So where does that leave clinicians and, more importantly, women themselves who are considering antidepressants in pregnancy. Women can certainly be reassured that any increased risk in absolute terms is not large. The baseline risk in the general population for ASD in children is around 1\%. The studies that find an association (and as we have seen these are not all studies) suggest the rate in children born to women taking SSRIs in pregnancy may be approximately double at around $2 \%$. It remains difficult to know whether this modest increase in risk is due to the medication being taken, to the mood disorder itself, to an overlap 
in genetic vulnerability or to other factors associated with mood disorders and antidepressant medication.

Decisions about taking medication in pregnancy are difficult, with no right and wrong answers. In helping women through this process, clinicians must weigh up the risks and benefits of all options, taking into account the woman's individual history and circumstances. It is important to recognise that episodes of severe psychiatric illness may have negative consequences for the woman, her baby and her family, and these must be weighed against what is known about the risks of taking medication. Although the communication of risk is a vital and difficult area of clinical practice and an emerging area of research, ${ }^{10}$ more work is clearly needed to address the particular issues around discussing psychotropic medication in pregnancy with women and their partners.

Depression in pregnancy and following childbirth is common, and is an illness with potentially serious consequences - suicide remains a leading cause of maternal death in the UK. ${ }^{11}$ Depression can be severe, with serious implications for the woman, her baby and her wider relationships but it is also clear that not all women finding themselves pregnant and taking antidepressants will have a history of major and severe affective disorder. For some women, episodes of depression may be mild and brief, and medication may not be appropriate.

A range of different treatment approaches may help women with depression and may include improved support, specific psychological and social interventions and, for some, treatment with medication. It is vital that women who become depressed in pregnancy can access appropriate and timely help. For some women with moderate to severe episodes of depression or with a history of severe mental illness, taking medication in pregnancy may be the most appropriate decision but it is vital that all therapeutic options are explored.

The use of antidepressant medication in pregnancy is increasing. Data from Denmark find that the rate of exposure increased from $0.2 \%$ in 1997 to $3.2 \%$ in $2010 .^{12}$ In the UK, antidepressant prescribing in pregnancy increased nearly fourfold from 1992 to 2006, with approximately 3\% of the cohort from 2001 to 2006 receiving antidepressants at some stage during pregnancy. ${ }^{13}$ A key question is whether this increased use reflects a greater recognition of major depression in women in the childbearing years or, more worryingly, the inappropriate medicalisation of normal sadness and distress. Considering pregnancy is the responsibility of all clinicians who instigate drug treatments in women of childbearing potential. The issues raised by the potential link between SSRIs and ASD emphasises that women should not be taking medication in pregnancy if they do not need to. For a woman taking an antidepressant and who is pregnant or considering starting a family, this is an excellent time to consider whether the medication is still or indeed has ever been required.
Ian Jones, MRCPsych, PhD, Vice-Chair, Section of Perinatal Psychiatry, Royal College of Psychiatrists, and National Centre for Mental Health, Cardiff University; Liz McDonald, MRCPsych, Chair, Section of Perinatal Psychiatry, Royal College of Psychiatrists, and East London NHS Foundation Trust, UK

Correspondence: Professor Ian Jones, National Centre for Mental Health Cardiff University, Hadyn Ellis Building, Maindy Road, Cathys, Cardiff CF24 4HQ, UK. Email: jonesir1@cf.ac.uk

First received 30 Jan 2014, final revision 14 Apr 2014, accepted 1 May 2014

\section{References}

1 Cole JA, Ephross SA, Cosmatos IS, Walker AM. Paroxetine in the first trimester and the prevalence of congenital malformations. Pharmacoepidemiol Drug Saf 2007; 16: 1075-85

2 Kallen BA, Otterblad Olausson P. Maternal use of selective serotonin re-uptake inhibitors in early pregnancy and infant congenital malformations. Birth Defects Res A Clin Mol Teratol 2007; 79: 301-8.

3 Kieler H, Artama M, Engeland A, Ericsson O, Furu K, Gissler M, et al. Selective serotonin reuptake inhibitors during pregnancy and risk of persistent pulmonary hypertension in the newborn: population based cohort study from the five Nordic countries. BMJ 2012; 344: d8012.

4 Grigoriadis S, VonderPorten $\mathrm{EH}$, Mamisashvili L, Roerecke $\mathrm{M}$, Rehm J, Dennis $\mathrm{CL}$, et al. Antidepressant exposure during pregnancy and congenital malformations: is there an association? A systematic review and metaanalysis of the best evidence. J Clin Psychiatry 2013; 74: e293-308.

5 Croen LA, Grether JK, Yoshida CK, Odouli R, Hendrick V. Antidepressant use during pregnancy and childhood autism spectrum disorders. Arch Gen Psychiatry 2011; 68: 1104-12.

6 Rai D, Lee BK, Dalman C, Golding J, Lewis G, Magnusson C. Parenta depression, maternal antidepressant use during pregnancy, and risk of autism spectrum disorders: population based case-control study. BMJ 2013; 346: f2059

7 El Marroun $\mathrm{H}$, White TJH, van der Knaap NJF, Homberg JR, Fernández G, Schoemaker NK, et al. Prenatal exposure to selective serotonin reuptake inhibitors and social responsiveness symptoms of autism: population-based study of young children. Br J Psychiatry 2014; 205: 95-102.

8 Sørensen MJ, Grønborg TK, Christensen J, Parner ET, Vestergaard M, Schendel $D$, et al. Antidepressant exposure in pregnancy and risk of autism spectrum disorders. Clin Epidemiol 2013; 5: 449-59.

9 Hviid A, Melbye M, Pasternak B. Use of selective serotonin reuptake inhibitors during pregnancy and risk of autism. N Engl J Med 2013; 369 2406-15.

10 Ahmed H, Naik G, Willoughby H, Edwards AG. Communicating risk. BMJ 2012; 344: e3996.

11 Cantwell R, Oates MR. Chapter 11: Deaths from psychiatric causes (from the Eighth Report of the Confidential Enquiries into Maternal Deaths in the United Kingdom, 2006-2008). Br J Obstet Gynaecol 2011; 118 (suppl 1): 132-42.

12 Jimenez-Solem E, Andersen JT, Petersen M, Broedbaek K, Andersen NL, Torp-Pedersen $C$, et al. Prevalence of antidepressant use during pregnancy in Denmark, a nation-wide cohort study. PLOS One 2013; 8: e63034.

13 Petersen I, Gilbert RE, Evans SJ, Man SL, Nazareth I. Pregnancy as a major determinant for discontinuation of antidepressants: an analysis of data from The Health Improvement Network. J Clin Psychiatry 2011; 72: 979-85. 